\title{
The nationalization of electoral cycles in the United States: a wavelet analysis
}

\author{
Luís Aguiar-Conraria • Pedro C. Magalhães • \\ Maria Joana Soares
}

Received: 23 May 2012 / Accepted: 12 December 2012 / Published online: 8 January 2013

(C) Springer Science+Business Media New York 2013

\begin{abstract}
We take a new look at electoral sectionalism and dynamic nationalization in presidential elections. We treat this problem as one of synchronism of electoral cycles, which we estimate by using wavelets. After providing a self-contained introduction to wavelet analysis, we use it to assess the degree and the dynamics of electoral synchronization in the United States. We determine clusters of states where electoral swings have been more and less in sync with each other and with the national cycle. Then, we analyze how the degree of synchronism of electoral cycles has changed through time, answering questions as to when, to what extent, and where has a tendency towards a "universality of political trends" in presidential elections been more strongly felt. We present evidence strongly in favor of an increase in the dynamic nationalization of presidential elections taking place since the 1950s, largely associated with a convergence in most (but not all) Southern states.
\end{abstract}

Keywords Electoral cycles synchronism $\cdot$ Nationalization $\cdot$ Wavelet analysis

JEL Classification $\mathrm{H} 70 \cdot \mathrm{C} 32 \cdot \mathrm{D} 72$

\author{
L. Aguiar-Conraria \\ NIPE and Economics Department, University of Minho, Braga, Portugal \\ e-mail: lfaguiar@eeg.uminho.pt \\ P.C. Magalhães ( $₫)$ \\ Department of Government, Georgetown University, Washington, DC, USA \\ e-mail:pcm43@georgetown.edu \\ P.C. Magalhães \\ Institute of Social Sciences, University of Lisbon, Lisbon, Portugal
}

M.J. Soares

NIPE and Department of Mathematics and Applications, University of Minho, Braga, Portugal e-mail: jsoares@math.uminho.pt 


\section{Introduction}

Half a century ago, E.E. Schattschneider noted an important change that seemed to be taking place in presidential electoral politics in the United States: since the 1950s, large majorities of the vote for one party or another in any state had become increasingly rare events, and a trend towards the "universality of political trends" was taking hold, through which swings from one election to the next were reflected in an increasingly uniform way across states (Schattschneider 1960: 90-93). Since then, the notion that presidential politics have become "nationalized" seems to have taken hold. ${ }^{1}$ Studies have confirmed the much greater strength of national forces in presidential elections when compared with congressional elections (Vertz et al. 1987), the rising uniformity of swings across states from one election to the other (Schantz 1992), and the rise of national forces driving presidential election returns (Bartels 1998).

At the same time, however, one of the most recurrent findings in the study of spatial patterns in American presidential elections is the persistence of a regionally-based sectionalism. In the context of the study of presidential elections, scholars concerned with this perennial problem (Turner 1914, 1926) have detected a sustained geographic preponderance of one party or another. Using the techniques of quantitative geography (Murray 2010), including factor, K-means clustering, and spatial autocorrelation analyses, researchers have confirmed, particularly since the pioneering work of Archer and Taylor (1981), the existence of regions characterized by the electoral preponderance of one of the parties (Republicans or Democrats) or, conversely, by a relative balance between them. ${ }^{2}$ These and other spatial patterns have been explained not only as a result of the fundamental organization of presidential elections (the state-by-state organization of the Electoral College-Clotfelter and Vavrichek 1980) but also as resulting from variations between regions in terms of political cultures (Elazar 1994), fundamental economic features (Agnew 1987), or levels of social and ethnic diversity (Hero 1998). Finally, their persistence has been interpreted as evidence against the notion that some sort of growing homogeneity in electoral behavior is occurring in the United States: the resilience of this sort of sectionalism "questions (...) the nationalization thesis" and reveals that "political regionalism is a contemporary and historical feature of the American landscape" (Heppen 2003: 191, 203).

The coexistence of these two apparently different diagnostics should remind us that the concept of "nationalization of politics" encompasses two different dimensions. The first is what Claggett, Flanigan, and Zingale (1984: 81-82) described as "convergence of partisan support", i.e., "the increasing similarity of geographic units" in terms of electoral support for the two parties, or what Morgenstern, Swindle, and Castagnola (2009: 1322) call "static/distributional nationalization," "the consistency of a party's support across a country at a particular point in time." However, there is a second dimension of the "nationalization of politics": "uniform response" (Claggett et al. 1984: 81-82) or "dynamic nationalization" (Morgenstern et al. 2009: 1322). Regardless of how partisan support remains distributed across different territorial sub-units, it is also important to know whether swings from one election to another take place uniformly (or not) across the country. It is therefore possible

\footnotetext{
${ }^{1}$ To be sure, this diagnostic is less clear in what concerns congressional elections, considering the uncertainty about the actual size of incumbency effects, "presidential coattails", or the causes behind the emergence of quality challengers in congressional elections. See, for example, Stokes (1967), Claggett et al. (1984), Kawato (1987), Brady et al. (2000), and Morgenstern et al. (2009). For a recent discussion of national forces in congressional elections, see Burden and Wichowsky (2010).
}

${ }^{2}$ See also Archer and Shelley (1986), Shelley et al. (1996), and Heppen (2003). 
that, while nationalization may increase from a "dynamic" point of view, sectionalism may persist from a "distributional" point of view.

This paper, however, calls attention to another way in which "nationalization" and "sectionalism" may coexist: the existence of sectional patterns in dynamic nationalization itself. By applying the tools of wavelet analysis to the national and state presidential election returns, we can, first, ascertain the degree to which electoral change at the national and state level has been synchronized since the beginning of the 20th century and the extent to which such synchronism has increased or decreased. Furthermore, this methodology will allow us not only a fine-grained analysis of the extent to which each of the states have been synchronized with electoral change at the national level, but also, most crucially, the detection of sectional patterns in this dynamic nationalization, by determining particular clusters of states that have remained detached or moved closer both to the national elections' and to each other's electoral cycles. In other words, unlike what most of the literature concerned with regional sectionalism has done so far, we can look for and detect spatial patterns, not on the level of support historically awarded by different states to different parties, but rather on the degree of uniformity of electoral change the states have displayed through time.

Finally, our analysis sheds further light on both when and how a general increase in the "universality of political trends" may have taken place. Schattschneider argued that the New Deal had been a crucial, but only a first step, in a change in the agenda of American politics. Comparing the directionality of electoral swings in the states and detecting the 1950s as a turning point in this respect, he concluded that the New Deal's change in public policy—-"the greatest in American history"- "was in its turn swamped a decade later by an even greater revolution in foreign policy arising from World War II and the Cold War." It was only the cumulative effect of these events that modified the nature of party alternatives and created a national political alignment that replaced the previous sectional alignment (Schattschneider 1960: 89). Others, however, suggest different timings and even trends. Schantz (1992), for example, argues that the major shift in this respect took place from 1928 to 1936, after which the mean deviation between swings in different groups of states and the national swing remained stable and at low levels. Bartels (1998: 285), albeit finding that the contemporary period was one of "unprecedented nationalization," finds "the magnitude of national forces increasing markedly over the first three decades of the 20th century, reaching a peak at the beginning of the New Deal era," and that the relative magnitude of national and subnational forces actually tipped "towards sub-national forces during the racial sorting-out of the 1950s and 1960s." In this paper, we revisit this discussion, using the cross-wavelet and phase-difference tools provided by wavelet analysis to determine when the increase in the synchronization of electoral cycles occurred and the states that contributed the most to that overall trend.

The study is structured as follows. In section two, we introduce the tools of wavelet analysis. With already broad usage in the physical and biological sciences, wavelet analysis is becoming recognized as a standard econometric tool (Crowley 2007; Aguiar-Conraria et al. 2012b; Kennedy 2008; Aguiar-Conraria and Soares 2011; Gallegati et al. 2011; Rua 2012). However, other than in economics, and to the best of our knowledge, wavelet analysis has never - with the single exception of Aguiar-Conraria et al. (2012a) - been used in other social sciences. We go further than the previous political science application of wavelet analysis by introducing the wavelet spectral distance matrix, which allows us, in section three, to compute distances for each pair of states and between each state and the United States in terms of the main features of their electoral cycles and to look into the spatial patterns of this synchronism, detecting clusters of states that, throughout American electoral history, have displayed more similar or dissimilar behaviors in terms of electoral change through 
time. In section four, we approach the issue of the strengthening dynamic nationalization of presidential elections with the help of cross-wavelet and phase-difference tools, addressing the issue of when did a trend towards increasing uniformity of electoral change across the United States begin to take hold.

\section{Electoral cycles and wavelet analysis}

Our starting point is the notion that electoral change in the United States has exhibited cyclical features. To be sure, a number of critiques of "realignment theory" have debunked the notion that presidential election returns are characterized by abrupt and rigidly periodic changes from one party to another (Lichtman 1976; Bartels 1998; Mayhew 2002). However, once we stay away from the notion of "critical elections," there is considerable evidence that election returns have displayed, at least since the late 19th century and at the national level, some sort of pendularity, in which the share of the vote for the major parties has ebbed and flowed in a fairly regular manner. Although controversy remains concerning the actual periodicity of those cycles and their prevalence throughout the entire American electoral history, empirical support for some sort of cyclicality has been shown robust to the use of a variety of techniques (Norpoth 1995; Lin and Guillén 1998; Merrill et al. 2008; AguiarConraria et al. 2012a).

From this starting point, the issue of dynamic nationalization in presidential elections can be framed in terms of the synchronization of electoral cycles both across territorial subunits and between those sub-units and what happens at the national level. If the overall variances in the time series of election returns in different sub-units are explained by similar predominant cycles, if there is coherence in time and predominant frequency between those time series, and if those oscillations in electoral support are synchronized, then one would be observing uniformity in electoral swings, i.e., "dynamic nationalization." The challenge is to devise a way to estimate the fundamental properties of these time series and to devise a metric that allows us to measure their similarity and dissimilarity and how it has evolved with time. We argue that wavelet analysis is particularly well-suited for this task.

Like Fourier spectral analysis, wavelet analysis allows us to determine whether cycles of a particular length play predominant roles in explaining the overall variance of a timeseries. Unlike Fourier spectral analysis, wavelet analysis reveals how the different periodic components evolve over time. In this section, we present a rigorous intuitive introduction to wavelet analysis. For a technically demanding text, the reader may consult Aguiar-Conraria and Soares (2013, forthcoming). One paper that we found useful when we started working on wavelets is the one by Cazelles et al. (2008).

\subsection{Wavelets and the time frequency analysis of cycles}

The theory behind Fourier analysis can be traced back to 1807, when Joseph Fourier showed that almost any periodic function could be written as a weighted sum of sines and cosines of different frequencies. Even if the function is not periodic, under some conditions, it still may be expressed as an integral of sines and cosines multiplied by a weighting function. In studying cycles, a sensible approach is to map the original variable, say $x(t)$, into the frequency domain, by means of the Fourier transform. Fourier spectral analysis has been used to estimate which cycles play predominant roles in explaining the variance of a time series. E.g., Merrill et al. (2008) relied on this technique to conclude that there was a predominant cycle in the North American national elections with a period of about 26 years. 


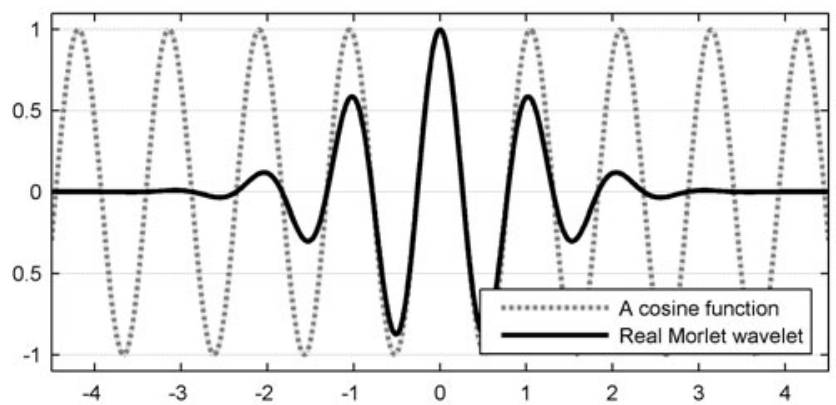

Fig. 1 A wavelet and a cosine function

Given $x(t)$, we denote by $X(\omega)$ its Fourier transform, here defined as

$$
X(\omega)=\int_{-\infty}^{\infty} x(t) e^{-i \omega t} d t=\int_{-\infty}^{\infty} x(t)[\cos (\omega t)-i \sin (\omega t)] d t
$$

where $i=\sqrt{-1}$ is the imaginary or complex unit. ${ }^{3}$ The main limitation of Fourier analysis is apparent in the above formula, where $X$ is a function only of $\omega$, the frequency, implying that the information about time is lost under the Fourier transform. This is the main advantage of wavelet analysis: its ability to provide information simultaneously in the time and in the frequency domains.

The minimum requirements imposed on a function to be called a wavelet involve a certain technical condition (known as the admissibility condition); for practical applications, however, a wavelet $\psi$ must be a function with finite energy (analogous to require that its variance is bounded), ${ }^{4}$ well-localized in time (i.e., have fast decay towards zero) and have zero mean (which means that the function has to wiggle up and down around zero). This is illustrated in Fig. 1.

Consider a variable $x(t)$ and a wavelet function $\psi$, possibly complex. The continuous wavelet transform (CWT) $)^{5}$ of $x$ with respect to $\psi$ is a function of two variables:

$$
W_{x}(\tau, s)=\int_{-\infty}^{\infty} x(t)\left[\frac{1}{\sqrt{s}} \bar{\psi}\left(\frac{t-\tau}{s}\right)\right] d t,
$$

where the bar denotes complex conjugation. ${ }^{6}$ The wavelet transform maps the variable into the time-scale domain. Parameter $\tau$ is a translation parameter controlling the location of the wavelet (in time). Parameter $s$ is a scaling or dilation factor that controls the width of the wavelet; increasing $s$ stretches it into a long wavelet function to measure long-run cycles (low frequency) while decreasing $s$ compresses it to measure short-run cycles (high frequency). We say that the wavelet analysis is performed in the time-frequency domain

\footnotetext{
${ }^{3}$ It should be observed that there are different conventions in the definition of Fourier transform; with the above convention, $\omega$ is an angular (or radian) frequency. The relation to the more common Fourier frequency $f$ is given by $\omega=2 \pi f$.

${ }^{4}$ This means that $\|\psi(t)\|^{2}=\int_{-\infty}^{\infty}|\psi(t)|^{2} d t<\infty$. Usually, $\psi(t)$ is normalized so that $\|\psi(t)\|=1$.

${ }^{5}$ There is also the Discrete Wavelet Transform (DWT), with which we will not deal. For an introduction to the DWT, the reader is referred to Crowley (2007).

${ }^{6}$ The conjugate of a complex number, $a+b i$, is simply $a-b i$. If a number is real, then the conjugate is the number itself. Therefore, this distinction is relevant only in the case of a complex wavelet.
} 
because there is a biunivocal (inverse) relation between scales and frequencies, and both terms can be used interchangeably.

\subsection{The wavelet choice and its localization properties}

Looking at Eq. (2), it should be clear that the wavelet transform is an amalgam of the original variable, $x(t)$, and the wavelet, $\psi$. Therefore, one must be careful with the wavelet choice. Several wavelet functions with different characteristics are available, such as the Paul, Daubechies, Haar and Cauchy. Some of them have nice names, like the Mexican hat, in honor of its characteristic shape.

When one is interested in studying the oscillatory behavior of a variable, it is almost mandatory to use a complex wavelet. To see this, note that, when we use a complex wavelet, $W_{x}(\tau, s)$ is a complex number that can be separated in its amplitude, $\left|W_{x}(\tau, s)\right|$, and phase (or phase angle), $\varphi_{x}(\tau, s): W_{x}(\tau, s)=\left|W_{x}(\tau, s)\right| e^{i \varphi_{x}(\tau, s)}$. The phase yields important information about the position of the variable in the cycle. We will explore this notion later, when we discuss the phase-difference.

By far, the most popular complex wavelet is the so-called Morlet wavelet, defined by

$$
\psi_{\omega_{0}}(t)=\pi^{-\frac{1}{4}} e^{i \omega_{0} t} e^{-\frac{t^{2}}{2}}=\pi^{-\frac{1}{4}}\left[\cos \left(\omega_{0} t\right)+i \sin \left(\omega_{0} t\right)\right] e^{-\frac{t^{2}}{2}},
$$

where $\omega_{0}$ is a localization parameter in the frequency domain. There are good reasons for the Morlet wavelet to be so popular. First, with the Morlet wavelet, the functions used in the analysis are given (essentially) by sines and cosines just like with the Fourier analysis. The main difference is the Morlet wavelet becomes a well-localized function by multiplication by a standardized Gaussian density function for $t$. Because of this, the concepts of frequency of the Fourier analysis and frequency of wavelet analysis are similar. This is a plus, especially because social scientists are more familiar with Fourier analysis. The wavelet in Fig. 1 is the real part of the Morlet wavelet, with $\omega_{0}=6$. $^{7}$

Second, the Morlet wavelet has optimal joint time-frequency localization in the following sense. The Heisenberg uncertainty principle states that certain pairs of physical properties cannot simultaneously be known to arbitrarily high precision. In our context, precision in frequency implies less precision in time. The Morlet wavelet reaches Heisenbergian uncertainty's theoretical lower bound. Moreover, it also reaches the best possible compromise between time and frequency accuracy. ${ }^{8}$

\subsection{The wavelet power spectrum: a fake and a real application}

In analogy with the Fourier power spectrum, the wavelet power spectrum is defined as

$$
W_{x}(\tau, s)=\left|W_{x}(\tau, s)\right|^{2} .
$$

\footnotetext{
${ }^{7}$ Although, strictly speaking, the Morlet function defined by (3) is not a "true" wavelet, since it has no zero mean, in practice, it can still be considered as a wavelet, provided that the parameter $\omega_{0}$ is sufficiently large (e.g., $\omega_{0}>5$ ). The case $\omega_{0}=6$ is the most common choice. This is so essentially because for this value, the wavelet can be considered to be a function of angular frequency $\omega_{0}=6$ (normal frequency $f=6 / 2 \pi \approx 1$ ) and, when scaled by $s$, it becomes a function of frequency $f \approx 1 / s$. Therefore, for this parameter choice conversion from wavelet scales $(s)$ to frequencies is almost immediate.

${ }^{8}$ Let $\mu_{t}$ and $\sigma_{t}$ and $\mu_{\omega}$ and $\sigma_{\omega}$ be the mean and standard deviation of the probability density functions defined by $|\psi(t)|^{2} /\|\psi(t)\|$ and by $|\Psi(\omega)|^{2} /\||\Psi(\omega)|\|^{2}$, respectively, where $\Psi(\omega)$ is the Fourier transform of $\psi(t)$. The most significant values of $\psi(t)$ and $\Psi(\omega)$ are attained in the so-called Heisenberg box: $H_{\psi}=$ $\left[\mu_{t}-\sigma_{t}, \mu_{t}+\sigma_{t}\right] \times\left[\mu_{\omega}-\sigma_{\omega}, \mu_{\omega}-\sigma_{\omega}\right]$. We say that $\psi$ is localized around the point $\left(\mu_{t}, \mu_{\omega}\right)$ with uncertainty given by $\sigma_{t} \sigma_{\omega}$. The Heisenberg uncertainty principle establishes that $\sigma_{t} \sigma_{\omega} \geq 1 / 2$. Moreover, for the Morlet wavelet, one has that $\sigma_{t}=\sigma_{\omega}=\frac{1}{\sqrt{2}}$, meaning that accuracy in time and in frequency are similar.
} 


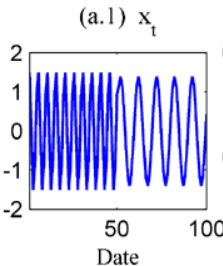

(a.3) Wavelet Power Spectrum of $x_{t}$

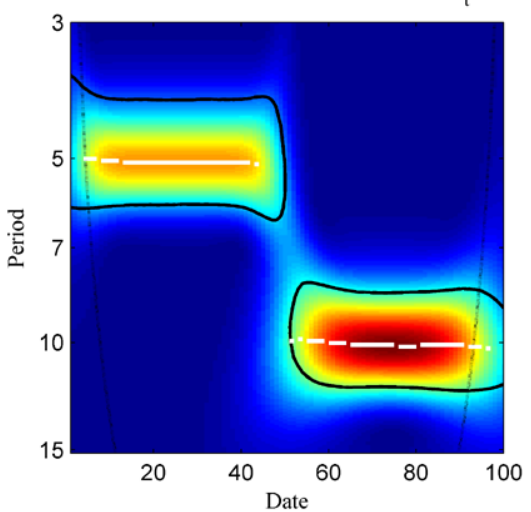

(a.2) FPS of $x_{t}$

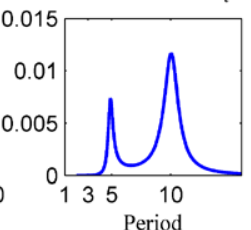

(b.1) $\mathrm{y}_{\mathrm{t}}$

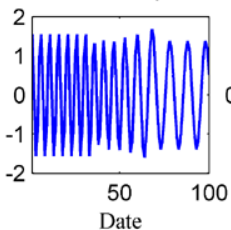

(b.3) Wavelet Power Spectrum of $y$

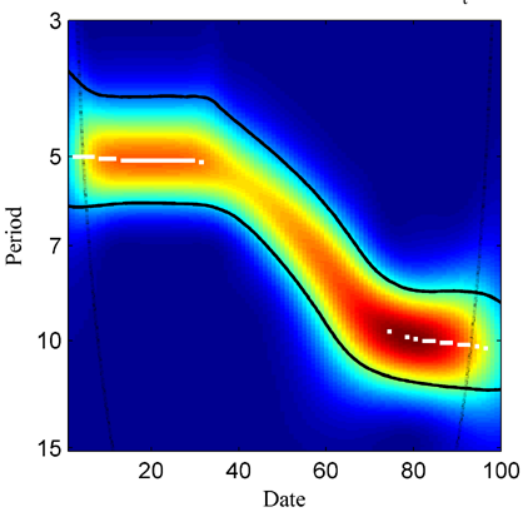

Fig. 2 Wavelet analysis of oscillatory signals with two period components. Series $x_{t}$ is characterized by a five-year cycle that, abruptly, changes to a 10 -year cycle at observation 51 . Series $y_{t}$ is characterized by a five-year cycle in the first 35 observations and a 10-year cycle in the last 30 observations. In between, the cycle gradually changes its periodicity from five to ten. In (a.2) and (b.2) we estimate the Fourier power spectrum of $x_{t}$ and $y_{t}$. In (a.3) and (b.3) we estimate the wavelet power spectrum of $x_{t}$ and $y_{t}$ (Color figure online)

This gives us a measure of the variance distribution of the time series in the timefrequency plane.

To illustrate how the wavelet power spectrum differs from the Fourier power spectrum, consider two variables that we construct: $x_{t}$ and $y_{t}$. Assuming that the data are annual, both are characterized by two cycles: one with a periodicity of five years and the other with a periodicity of ten years. However, while for $x_{t}$ this change is abrupt, and occurs at observation 51, for $y_{t}$ the change is gradual, slowly evolving from observation 36 until observation 71 , when it becomes a 10 -year cycle. ${ }^{9}$

In Fig. 2, these series, as well as their Fourier power spectrum and their WPS, are represented. In the pictures with the Fourier power spectrum (a.2 and b.2), the two main cycles are well identified; however the picture completely misses the dynamics of the cycles. From the power spectrum, it is impossible to know the period in which each cycle was prevalent as well as identify when the change occurred and if it was abrupt or smooth. Notice that, in both cases, the Fourier power spectrum yields basically the same estimation. In one sentence: time information is lost.

In the bottom, we have the wavelet power spectra. We have time on in the horizontal axis and frequency - converted into cycle periods — on the vertical axis. The value of the wavelet power spectrum is captured by colors. Cold colors correspond to low power, indi-

\footnotetext{
${ }^{9}$ We have written a wavelet toolbox in Matlab. The toolbox, all of the data and codes can be at https://sites. google.com/site/aguiarconraria/joanasoares-wavelets. All of the data and codes used can be found there. The toolbox is quite user-friendly and comes with several examples and a quick user's guide.
} 
Fig. 3 The wavelet power spectrum of the Democratic share of the vote in presidential elections (Color figure online)

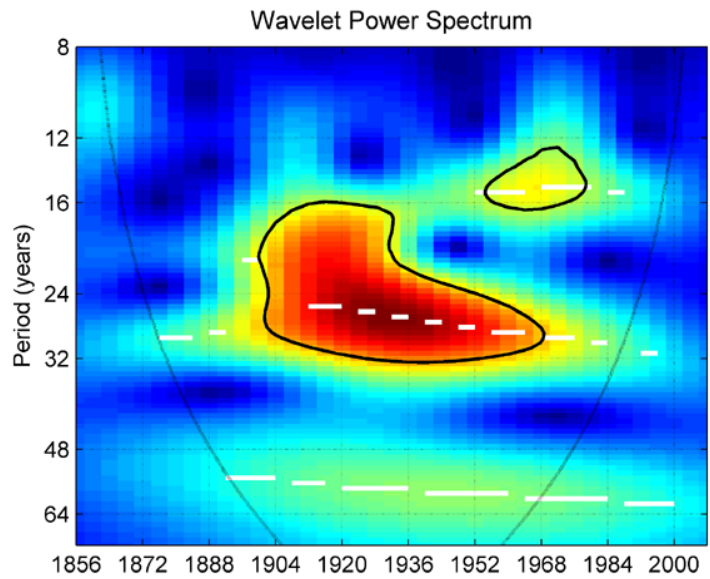

cating low volatility at the specified time and frequency, while warm colors correspond to regions of high power. The colors range from blue to red. The black contour indicates $5 \%$ significance $^{10}$ and the faded black lines capture the cone of influence (COI), indicating the region affected by edge effects. ${ }^{11}$ The white lines show the local maxima of the wavelet power spectrum. Had we relied on three-dimensional graphs, instead of colors, these would correspond to the peaks of the mountains.

In both cases, the wavelet power spectrum captures quite well the dynamics of the cycles. In the first case, the abrupt change is perfectly clear, with the red region moving abruptly from period five to period 10. In the second case, this change is gradual.

Basically, while the Fourier transform is silent about changes that happen across time, with wavelets we estimate the power spectrum as a function of time and, therefore, we are able to simultaneously identify the period of the most important cycles as well as their dates.

Figure 3, taken from Aguiar-Conraria et al. (2012a), displays the wavelet power spectrum for the Democratic share of the two-party vote from 1856 to 2008 in presidential elections. ${ }^{12}$ By applying wavelet analysis to American national presidential electoral returns, the authors showed that the predominant cycles that had been identified in previous studies were in fact transient, failing to characterize the entire period under examination.

This picture reveals the existence of the 26/27-year cycle identified earlier by Lin and Guillén (1998) and Merrill et al. (2008), but also that such a cycle is localized temporally starting at the turn of the 20th century but dissipating by the end of the 1960s. Furthermore, it shows a transitional 14-year cycle between the late 1950s and 1980, as well as (weak, statistically not significant) evidence of the coexistence of these cycles with a long cycle of 60 years.

\footnotetext{
${ }^{10}$ To perform significance tests of wavelet measures, we fit an AR(1) model and construct new samples by drawing errors from a Gaussian distribution with a variance equal to that of the estimated error terms. For each time series (or pair of time series) we perform the exercise 5000 times, and then extract the critical values.

${ }^{11}$ As with other types of transforms, the CWT applied to a finite length time series suffers from border distortions due to the fact that the values of the transform at the beginning and the end of the time series involve missing values of the series which are artificially prescribed. In this area, the results have to be interpreted carefully.

${ }^{12}$ All data used in this paper were provided by the American Presidency Project at UC Santa Barbara (http:// www.presidency.ucsb.edu).
} 


\subsection{The cross wavelet transform and the phase-difference}

So far, we have seen only how to analyze a single time series. However, with wavelet analysis one also has the ability to deal with the time-frequency dependencies between two time series. ${ }^{13}$ This is allowed by using the concepts of cross wavelet power, wavelet coherency, and phase-difference, which are natural generalizations of the basic wavelet analysis tools. The cross-wavelet transform of two time series, $x(t)$ and $y(t)$, is defined as $W_{x y}(\tau, s)=$ $W_{x}(\tau, s) \bar{W}_{y}(\tau, s)$. The cross-wavelet power of two time series, $\left|W_{x}(\tau, s)\right|$, depicts the local covariance between two time series at each time and frequency. In analogy with the concept of coherency used in Fourier analysis, given two time series $x(t)$ and $y(t)$ one defines their wavelet coherency:

$$
R_{x y}(\tau, s)=\frac{\left|S\left(W_{x y}(\tau, s)\right)\right|}{\sqrt{\left|S\left(W_{x x}(\tau, s)\right) S\left(W_{y y}(\tau, s)\right)\right|}},
$$

where $S$ denotes a smoothing operator in both time and scale. ${ }^{14}$ It ranges from zero (no coherency) to 1 (strong coherency). This quantity can be interpreted as a local correlation coefficient in the time-frequency space.

One of the major advantages of using a complex-valued wavelet is that we can compute the phase of the wavelet transform of each series and thus obtain information about the possible delays in the oscillations of the two series as a function of time and frequency, by computing the phases and the phase-difference. The phase is given by $\varphi_{x}(\tau, s)=$ $\tan ^{-1}\left(\Im\left(W_{x}(\tau, s)\right) / \mathfrak{R}\left(W_{x}(\tau, s)\right)\right)$ and the phase-difference by

$$
\varphi_{x y}=\tan ^{-1}\left(\frac{\Im\left(W_{x y}(\tau, s)\right)}{\Re\left(W_{x y}(\tau, s)\right)}\right),
$$

where, for a given complex number, $\Re()$ and $\Im()$ denote, respectively, its real part and its imaginary part.

In our application, where the features of national and state-level election returns are compared, a phase-difference of zero indicates that the time series of election returns at the national and at the state level move together at the specified frequency; between 0 and $\pi / 2$, the series move in phase, with the national electoral cycle leading the state cycle; between $-\pi / 2$ and 0 , then it is the state that leads; between $\pi / 2$ and $\pi$, the series are out of phase (negatively correlated), with the state leading; and, finally, between $-\pi$ and $-\pi / 2$, they are out of phase, with the national cycle leading.

For example, in Fig. $4,{ }^{15}$ on the left, we show the wavelet coherency between the Democratic share in presidential elections in Maine and the United States as a whole. Dynamics change both across time and frequencies. If one focuses on the cycles with periods in the range of 22-32 years, it is obvious that a very strong coherency exists between Maine and the rest of the nation. The phase-difference that corresponds to these frequencies, the red line in the bottom picture on the right, is above zero (and below $\pi / 2$ ). This tells us that the electoral cycle in Maine lags the national cycle.

At shorter run frequencies, in 12-16 year range, we also observe a highly coherent region between the early 1950s and early 1990s. For these years, the phase-difference (top picture

\footnotetext{
${ }^{13}$ For a generalization to several variables, see Aguiar-Conraria and Soares (2013, forthcoming).

${ }^{14}$ Smoothing is necessary; otherwise, just as with Fourier coherency, it would be identically one at all scales and times. Time and scale smoothing can be achieved, e.g., by convolution with appropriate windows.

${ }^{15}$ In Sect. 5, when these results are discussed more deeply, we also discuss our estimation choices.
} 
(a) Coherency between Maine and USA

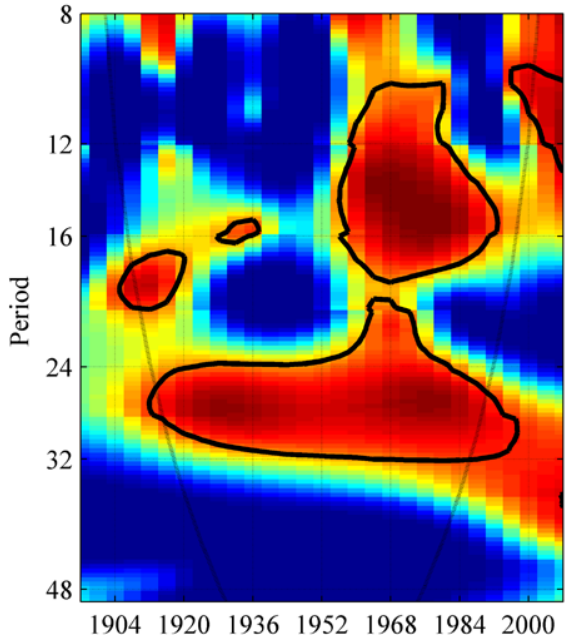

(b) 12 16 frequency band

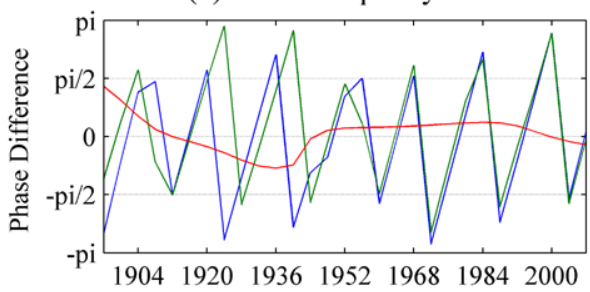

(c) 22 32 frequency band

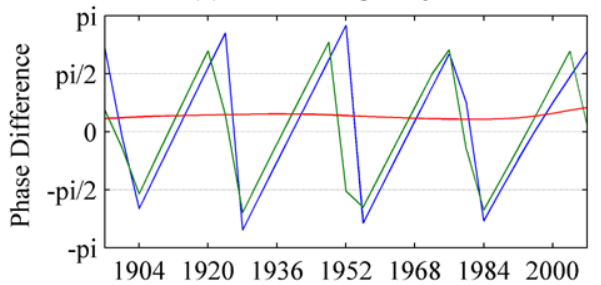

Fig. 4 On the left: wavelet coherency between Maine and the United States. The black contour designates the $5 \%$ significance level. The color code for coherency ranges from blue (low coherency-close to zero) to red (high coherency-close to one). On the right: phase and phase-difference. The green line represents the National phase, and the blue line represents the state's phase. The red line gives us the phase-difference between the two series (Color figure online)

on the right) is also slightly above zero, showing that electoral cycles in this state lag the national cycles. This is an illustration of the type of information that one can extract from the presented wavelet tools.

\subsection{Distance between two wavelet transforms}

For our purposes, we need to measure the dissimilarities between the wavelet transforms of two time series, say $x_{t}$ and $y_{t} \cdot{ }^{16}$ Comparing wavelet transforms is like comparing two images. Direct comparison is not suitable because there is no guarantee that regions of low power will not overshadow the comparison.

We follow Aguiar-Conraria and Soares (2011) and compute the Singular Value Decomposition of the matrix $W_{x} W_{y}^{H}$, where $W_{y}^{H}$ is the conjugate transpose of $W_{y}$, to focus on the common high power time-frequency regions. Because this method extracts the components that maximize covariances, the first extracted components correspond to the most important common patterns of the wavelet transforms. With the Singular Value Decomposition we compute just a few vectors-the leading patterns, $l_{x}^{k}$ and $l_{y}^{k} ; k=1, \ldots, K$, and singular vectors, $u_{x}^{k}$ and $u_{y}^{k} ; k=1, \ldots, K$, with $K<F^{17}$ —which will approximately reconstruct the original matrices: $W_{x} \approx \sum_{k=1}^{K} u_{x}^{k} l_{x}^{k}$ and $W_{y} \approx \sum_{k=1}^{K} u_{y}^{k} l_{y}^{k}$.

\footnotetext{
${ }^{16}$ Note that we are comparing the wavelet transforms, and not the power spectrum. Therefore we are preserving the information given by the imaginary part.

${ }^{17}$ In this paper, we use $K=3$.
} 
As in Aguiar-Conraria and Soares (2011), to compare the wavelet spectra between two regions, $x$ and $y$, we compute the following distance:

$$
\operatorname{dist}\left(W_{x}, W_{y}\right)=\frac{\sum_{k=1}^{K} \sigma_{k}^{2}\left[d\left(l_{x}^{k}, l_{y}^{k}\right)+d\left(u_{x}^{k}, u_{y}^{k}\right)\right]}{\sum_{k=1}^{K} \sigma_{k}^{2}},
$$

where $\sigma_{k}$ are singular values (obtained in the SVD decomposition) and where the distance $d(u, v)$ between two vectors is computed by measuring the angle between each pair of corresponding segments, defined by the consecutive points of the two vectors, and taking the mean of these values. This is not as trivial as it may seem, because, since we are using use a complex wavelet, the components of leading vectors and leading patterns are complex numbers. Therefore, we need to define an angle in a complex vector space, for which there is no mathematical consensus. There are two reasonable approaches, one using the Hermitian angle, the other using an extension of the Euclidean angle. We will use the Hermitian approach. ${ }^{18}$ Using the Euclidean would deliver similar results, except where noted.

We now can use these tools to examine elections in the states, determining the cyclicality of election returns in each one (with the wavelet power spectra), comparing it state to state and between each state and the national outcomes (with the wavelet spectral distances as described in this section), determining with cluster analysis what sets of states exhibit most similar cyclicality, and, finally, use the cross-wavelet and phase-difference tools to look at the timing of closer synchronization among states. This is what we do in the next two sections.

\section{The geography of electoral cycles}

That there is a geography of the distribution of party support in presidential elections is, by now, relatively well established in the literature. But what can we say about the geography of electoral change? What clusters of states emerge when we look for the synchronicity of their electoral cycles, both with the national cycle identified in Fig. 3 and among each other?

We use data for 45 states from 1896 until 2008, ${ }^{19}$ and compute the Democratic share of the two-party vote for all 29 presidential elections in all those states. ${ }^{20}$ Figure A1, which can be consulted in an online appendix, ${ }^{21}$ shows the continuous wavelet power spectra of

\footnotetext{
${ }^{18}$ For the mathematically oriented researcher: consider two complex vectors, $a$ and $b$. Define the Hermitian inner product, $\langle a, b\rangle_{C}=a^{H} b$ and the corresponding norm, $\|a\|=\sqrt{\langle a, a\rangle_{C}}$. The Hermitian angle, $\Theta_{H}$, between $a$ and $b$ is obtained by the formula $\cos \left(\Theta_{H}\right)=\left|\langle a, b\rangle_{C}\right| /(\|a\|\|b\|)$.

${ }^{19}$ The only excluded states are Alaska, Arizona, Hawaii, New Mexico, and Oklahoma, as they only achieved statehood after 1896.

${ }^{20}$ The only exception is for the 1912 presidential run. In that election, Theodore Roosevelt failed to receive the Republican nomination. Roosevelt created the Progressive party and ran for president, dividing the Republican electorate. For this individual election, we compare the votes of the Democratic candidate (Woodrow Wilson) with the total of the votes of the other two major contenders (William Taft and Roosevelt). A more recent case of a third party candidate receiving a large share of the vote (19\%) is Ross Perot in 1992. However, extant research shows that, rather than affecting one particular party, Perot voters would have been split almost evenly between the candidates of the two major parties (Alvarez and Nagler 1995). More generally, Merrill et al. (2008) show that the detection of cycles in US presidential elections is mostly insensitive to different ways of handling third-party candidates.

${ }^{21}$ The online appendix, containing Table A1 and Figs. A1 and A2, is available at: http://sites.google.com/site/ aguiarconraria/Online_Appendix_PUCH.pdf.
} 
the Democratic share of the vote for the national aggregate (as in Fig. 3) and in all 45 states considered. We assess the statistical significance against the null hypothesis of an AR(1).

Looking at the time-frequency decomposition, some interesting facts are revealed. The persistent 27-year cycle (until the 1960s) and the transient 14-year cycle between early 1950s and 1980 that we found for the United States as a whole is closely replicated in several states, such as, among others, Maine, Ohio, Maryland, New Hampshire, New York, and Pennsylvania. But if these states seem to replicate the basic cyclicality found at the national level, the same does not occur with others. For example, in Tennessee, a 10-14 year cycle is very strong between 1960 and 1990, while in Texas one can find a cycle at these same frequencies before 1950, and so on. In sum, it is clear that the time series of presidential election returns in the different states have different properties and that not all of them resemble closely the general ebb and flow of election results detected at the national level.

However, these sorts of visual comparisons become of little use with so much information, and we need to find summary measures of the similarity of cycles between states and the national aggregate. Furthermore, comparisons of wavelet power spectra may be deceptive, since they reveal no information about the phase. ${ }^{22}$ Therefore, even if two entities share a similar high power region - such as, for example, the United States and, say, Virginiaone cannot infer that their electoral cycles are alike. It is possible that, although cycles have a similar periodicity, while in one entity the Democratic share is increasing in a particular period, it is decreasing in other at the same time. Thus, based on formula (7) (multiplied by 100) we compute the pairwise dissimilarity index between the wavelet spectra that characterize election returns nationally and in the states. In Table 1, we show the dissimilarity between each state's electoral cycle and the national cycle. ${ }^{23}$

As explained in Sect. 2.5, this index takes into account both the real and the imaginary part of the wavelet transform. A value very close to zero means that two entities have a very similar wavelet transform. This, in turn, implies that the two entities being compared (either state with national aggregate or state with state) share the same high power regions and that their phases are aligned. This means that (1) the contribution of cycles at each frequency to the total variance is similar between both states, (2) this contribution happens at the same time in both states and, finally, (3) the ups and downs of each cycle are taking place simultaneously in both states. In this sense, we say that a value close to zero between entities means that their electoral cycles are highly synchronized.

Table 1 reveals that there are 24 states where we can reject, with $p<0.05$, the null hypothesis that the national cycle and the cycles in these states are not synchronized, a number of states that extends to 33 if we relax the significance level to $p<0.10$. To put it differently, there are 12 states that, throughout the period under analysis (from 1986 to 2008), seem clearly out of sync with the national cycle. It does not take long to realize what unit they form: they are all the eleven members of the former Confederate States of America, plus Kentucky.

In contrast, the ten states whose electoral cycles are more aligned with the national cycle are Ohio, Maine, New Hampshire, New Jersey, California, Wyoming, Iowa, Connecticut, Indiana, and North Dakota. Note again that the fact that these states have their electoral

\footnotetext{
${ }^{22}$ This is so because the phase information is obtained from the imaginary part of a complex number. However, the wavelet power spectrum is the square of an absolute value and the absolute value transforms a complex number into a real number.

${ }^{23}$ By "national," we mean the aggregate electoral result of the states included in our sample. When we compute the distance between each state and the national aggregate defined in this way, we exclude that state from the aggregate.
} 
Table 1 Dissimilarity index between the national and the states' electoral cycle

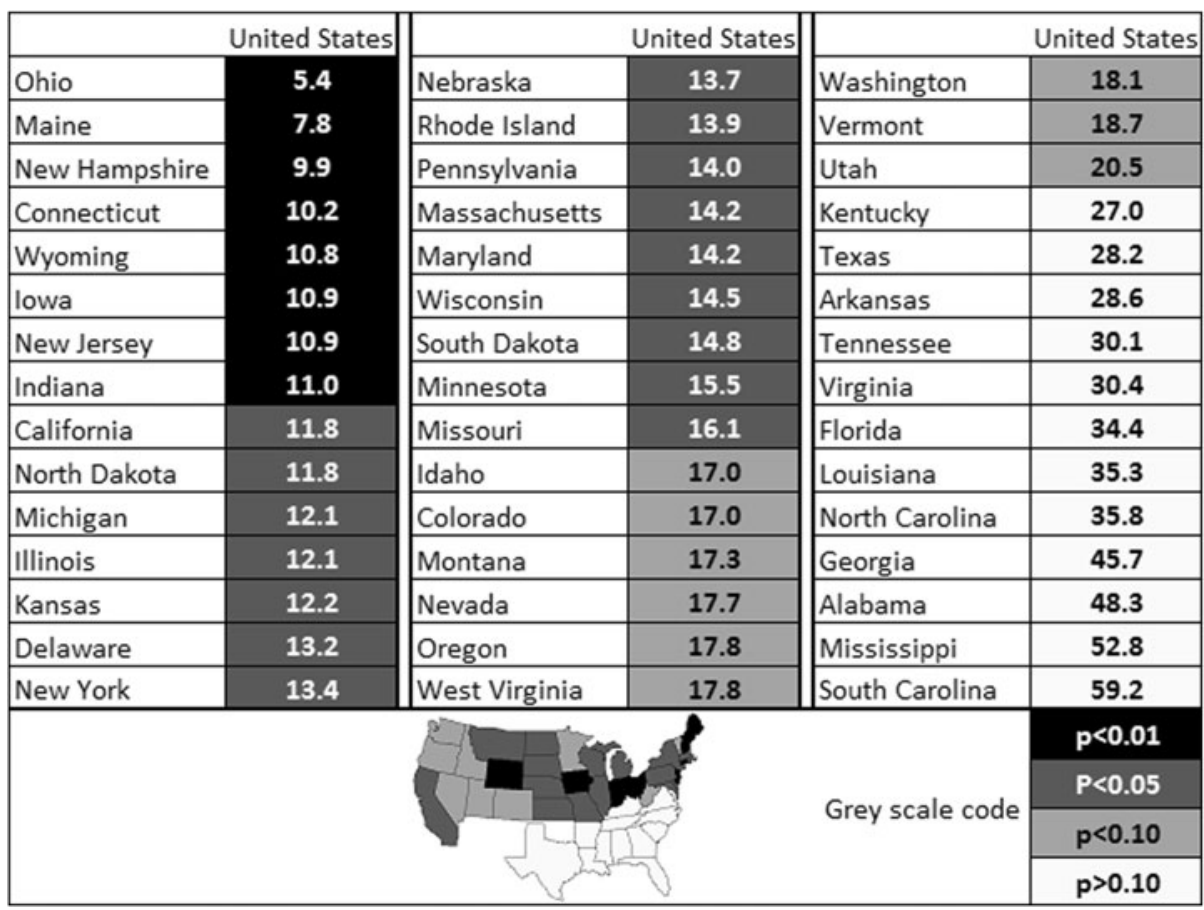

cycles synchronized with the national cycle does not mean that the candidate who wins in these states is the candidate who wins the country, or that the distribution of the partisan vote has been similar to that of the national aggregate. So, for example, it may seem obvious that a bellwether state like Ohio has closely followed the cyclicality at the national level. However, the list of most "aligned" states also includes "red states" like Wyoming or North Dakota, where Republican presidential candidates have won the electoral votes in all but one presidential election since 1952 (in fact, since 1940 for North Dakota), as well as states that, at least since the early 1990s, have been considered "safe" for Democrats (such as Maine, New Jersey, California, or Connecticut). What they share is the fact that, in spite of this, the swings around the mean have nevertheless been quite synchronized with what occurs at the national level. Finally, this analysis also tells us nothing about the distribution of the vote in the South. However, it does tell us that, contrary to what occurs in the remaining states, there is no evidence that the national ebb and flow of election returns we showed in Fig. 3 has generally been reflected, when the broad 1896-2008 period is considered, in the old Confederacy states.

We can also have a look at the pairwise dissimilarity between the electoral cycles in the 45 states under analysis. However, that table (Table A1, in the online appendix) has just too much information to be easily readable (more than 900 entries). Thus, we try to visualize this matrix by performing some clustering analysis. We produce a hierarchical tree clustering. The idea is to group the states according to their similarities. We follow a bottom up approach. We start with the 45 states and group, in cluster, the two most similar states, say C1 and C2 (New Jersey and New York, to be more precise). In the second round, states $\mathrm{C} 1$ and $\mathrm{C} 2$ are replaced by a combination of the two, say C46. Now, one has to build a new matrix, not only with the distance between the 44 remaining states, but also with the 


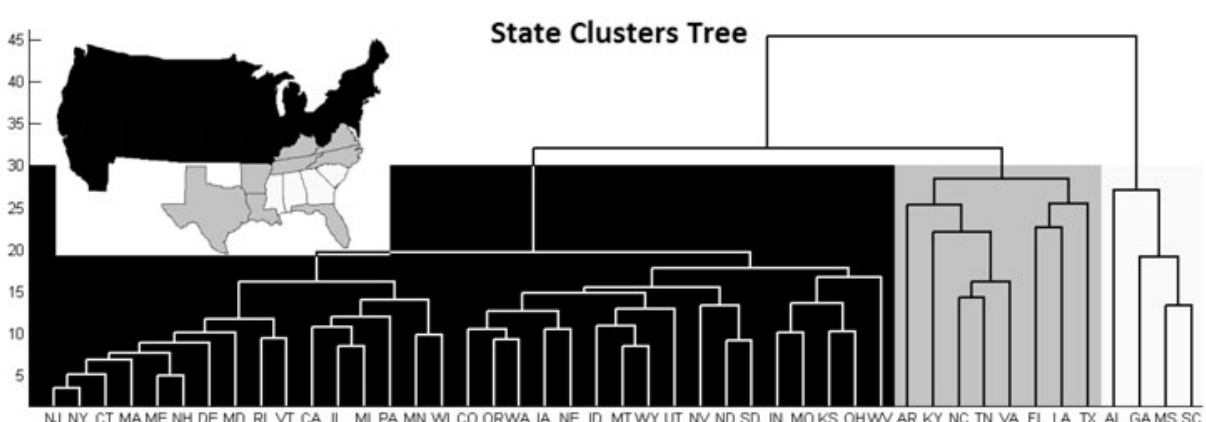

Fig. 5 Hierarchical tree clusters

distance between each state and C46 (which we consider to be the average of the individual distances). The procedure continues until there is only one cluster with all the states.

In Fig. 5, we can see the result of this hierarchical clustering. Depending on how demanding one is in the definition of a cluster, one can identify several clusters. Matlab's default results in partitioning the tree into three clusters. A big cluster of several states, whose electoral cycles are relatively similar, emerges. Note that this cluster of states coincides exactly with those that, in Table 1, we showed to have an electoral cycle significantly (at least at $10 \%$ level) synchronized with the cycle of national election returns. Then, among those states that were not synchronized with the national cycle, two additional clusters emerge when we make pairwise comparisons. It should not be by now a surprise that, on a longrun perspective, those two clusters would contain the Southern states. However, the results do identify an additional cluster containing the most asynchronous electoral cycles, which includes Alabama, Georgia, Mississippi and South Carolina, i.e., four of the five states that comprise the traditionally defined "Deep South."

Although suggestive, the clustering tree has some limitations that could conceivably distort the analysis. Since each state is linked solely to one other state (or cluster of states), one may lose sight of the whole picture. An alternative approach is to use the dissimilarity matrix as a distance matrix and map the states on a two-axis system. The idea is to reduce the dissimilarity matrix to a two-column matrix. This new matrix, the configuration matrix, contains the position of each state on two orthogonal axes. Therefore, we can position each state on a two-dimensional map. This cannot be performed with perfect accuracy because the dissimilarity matrix does not represent Euclidean distances. Its interpretation should be ordinal. Therefore, the goal is not to reproduce the "distances" given by Table A1 on a map, but rather to produce a map with pairwise distances that reproduce, as much as possible, the ordering of Table A1. We use Kruskal's (1964a, 1964b) stress algorithm and minimize the square differences between the distances on the map and the "true distances" given in Table 2. Figure 6 displays this map. Again, although the precise frontiers are, naturally, somewhat arbitrary, ${ }^{24}$ it remains possible to identify three clusters of states that coincide with the information we had extracted from the clustering tree: a set of core states; the "Outer South"; and the "Deep South."

In sum, these results reveal that there indeed has been a regional sectionalism in presidential election returns in the United States that has so far remained mostly unnoticed in

\footnotetext{
${ }^{24}$ With the exception of the largest cluster, which, as we have seen, includes all of the states that have an electoral cycle significantly synchronized with the national cycle.
} 
Fig. 6 Multidimensional scaling map. The figure plots in a two-dimensional scale the dissimilarities across states

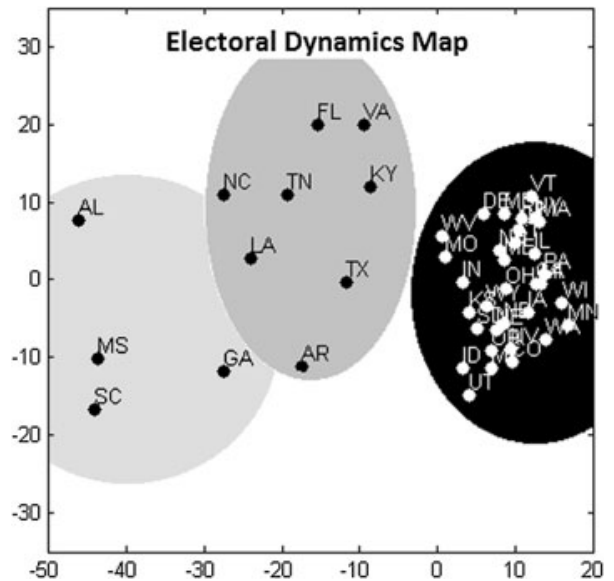

studies of quantitative political geography. Rather than being based on the historical electoral preponderance of one party or another, it is a sectionalism based on the extent to which particular regions have displayed swings from one election to another that are synchronized both with the national cycle and with each other. We found two clusters of states that have exhibited greater dissimilarity both from the "national" cycle and from the "core" states. These two clusters comprise together all of the old Confederacy plus Kentucky, but are internally differentiated in such a way as to separate the Deep South (with the exception of Louisiana) from the remaining Southern states. Kentucky is a "bordeline" case from another perspective: had we used the Euclidean angle, rather than the Hermitian, to compute the distance, Kentucky would have appeared in the first cluster. All remaining main results would stand.

\section{The dynamics of dynamic nationalization}

We can now move ahead to the second major issue at stake: has the degree of uniformity of electoral swings in the states increased with time? Besides, armed with the tools of wavelet analysis, we can answer an additional question: if synchronism has indeed increased, which states contributed the most to that overall trend?

We approach this issue by using the cross wavelets and phase-difference tools. With cross wavelets, we can estimate the coherency between cycles in different entities. Regions of high coherency between two entities are synonymous with strong local (both in time and frequency) correlation. Then, the phase-difference gives us information on the delay, or synchronization, between oscillations of the two time series for a given frequency. By estimating it, we can observe whether there are tendencies towards convergence in electoral cycles between the states and the national aggregate, localize those tendencies in time, and distinguish those states where convergence is observable from those where it is not. This is a major advantage of wavelet analysis when compared with other traditional methods. If we were using the traditional spectral analysis, we would lose the time information, making it impossible to analyze dynamic convergence. On the other hand, if we were using traditional time-domain methods (such as Granger causality tests), we would miss the information on frequencies. 
Figure 7 shows, for a small sample of four states provided here as an example, ${ }^{25}$ the coherency between the national cycle in the Democratic share of the two-party vote and the cycle for the same share of the vote in each of those states. We also estimate the phase of the oscillations at the national and state level, as well as their phase-difference. Given that, in Fig. 3, we identified two main national cycles, one at the 14-year frequency and the other at the 27-year frequency, we focus our phase-difference analysis on these cycles. So, for each state, we calculate the average phase and phase-difference for the 12-16 and for the 22-32 frequency bands.

We can immediately appreciate some interesting dynamics in these four illustrative cases. For example, South Carolina, like the other states we identified early on as belonging to the Deep South's most peripheral cluster-Alabama, Georgia and Mississippi-shows, as could be expected, very few regions of high coherence with the national cycle. Furthermore, the phase-difference shows that South Carolina's electoral cycle, besides not being aligned with the rest of the country, also exhibits no tendency to converge with the national cycle. If anything, as time goes by, South Carolina's electoral cycle, as well as those of the other states in this Deep South cluster (see Fig. A2 in the online appendix) is diverging more and more.

In contrast, if we focus on North Carolina, as well as on the "Outer South" cluster of states - the remaining old Confederacy states plus Kentucky — we do observe some amount of convergence with the national electoral cycle. In most cases (see Fig. A2), we find that it is at about 1950 that these states' phases reach convergence with the national phases, especially in the 12-16 year frequency band. Interestingly, there is one exception: Louisiana is the only one of the states in the second cluster where convergence in cycles with the national aggregate is reached at a later point in time, at about 1970. This seems to have been enough, however, to have brought Louisiana out of the "Deep South" cluster where, one might argue, it originally belonged.

Presidential election returns in Ohio, which according to Table 1 is the most aligned state, show many regions of high coherency and highly synchronized oscillations with the national cycle. ${ }^{26}$ However, its phases reveal that Ohio's electoral cycles have been slightly lagging the national cycle, although it is also clear that even in that regard there has been a convergence since mid-century. We can also identify some states that are very much synchronized for some periods and some frequencies, but not for others. North Carolina is one such example. In the first half of last century, there is a region of high coherency at the 27-years frequency, while in the second half the high coherency shifts to the 12-18 year frequency. In this latter case, one can also see that the phases are perfectly aligned with the national phase. Finally, if one had to choose the "leader state," that choice would fall on North Dakota, whose cycles have persistently been leading the national cycles on both frequency bands.

Inevitably losing some detail, we can summarize the overall findings in Fig. A2 in two ways: aggregating periods in time or aggregating states. First, we divided our observations into two subsamples, the first running from 1896 until 1952 and the second from 1952 to 2008 , i.e., using the generic turning point in terms of the "universality of political trends" suggested by Schattschneider's original analysis. We then computed our dissimilarity index for each sub-sample, in order to determine the states that converged to the core and those that did not. Figure 8 displays the variation observed from the first to the second sub-samples

\footnotetext{
${ }^{25}$ It would be too fastidious to include the coherencies and phase-differences of 45 states here. Figure A2 (in the Appendix) shows the results for every state.

${ }^{26}$ Similar conclusions would apply to other states in the first "core" group identified in the cluster analysis, like Michigan, Pennsylvania, Washington, New Jersey, Minnesota, and others.
} 

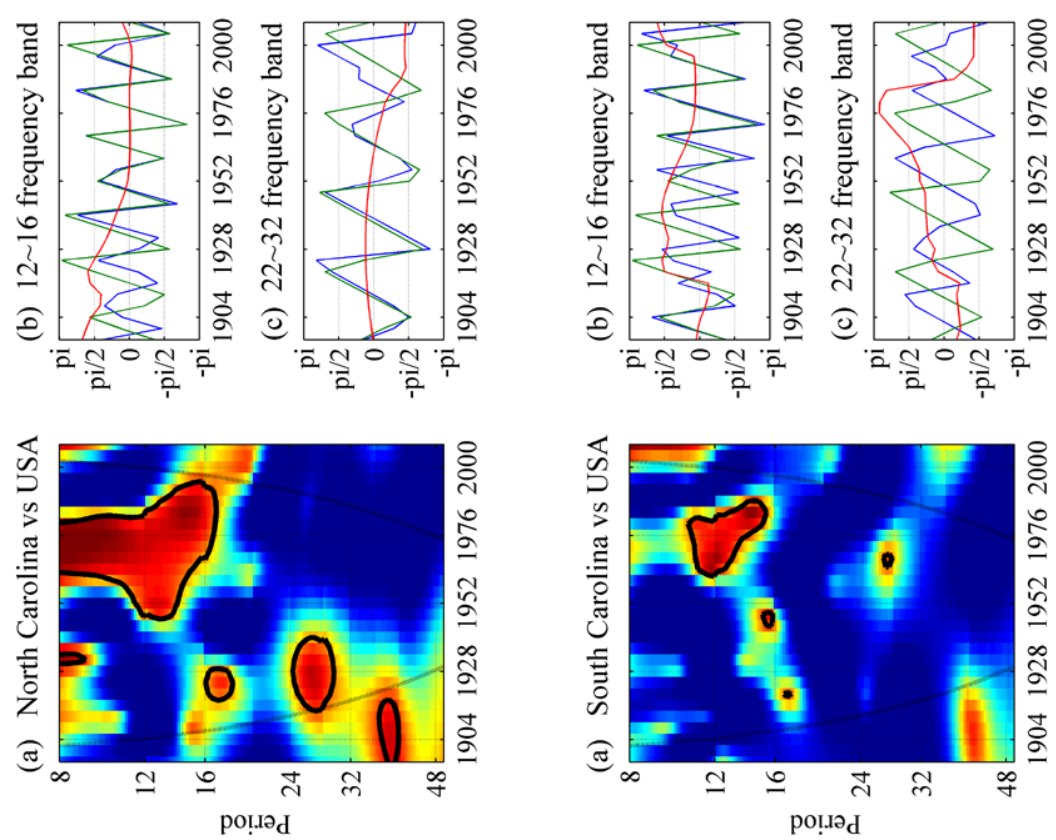

ن்

跣

8

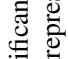

可

年

in

$\stackrel{乛}{\Xi}$

of

过包

牙造

离言

若

웜

행

\&

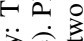

웡

늘

ठ용

당

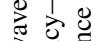

3 ฮै

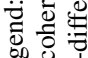

S.

० 를
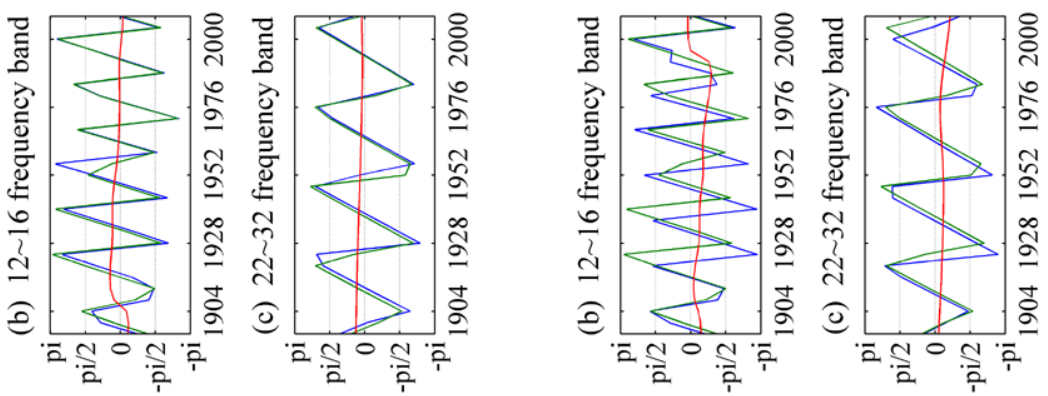

릴

氙

ㅇㅇㅇ

空

둔 용

踏

\%

츨.

范宛

해용

吾焉
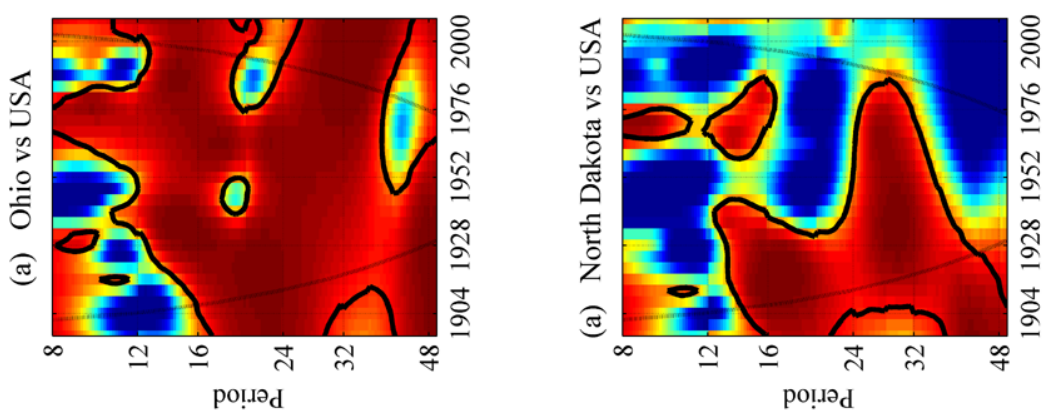

号

를

可

8 品

원

정

峁

응

总总

\&

ธิ

几 풍

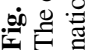




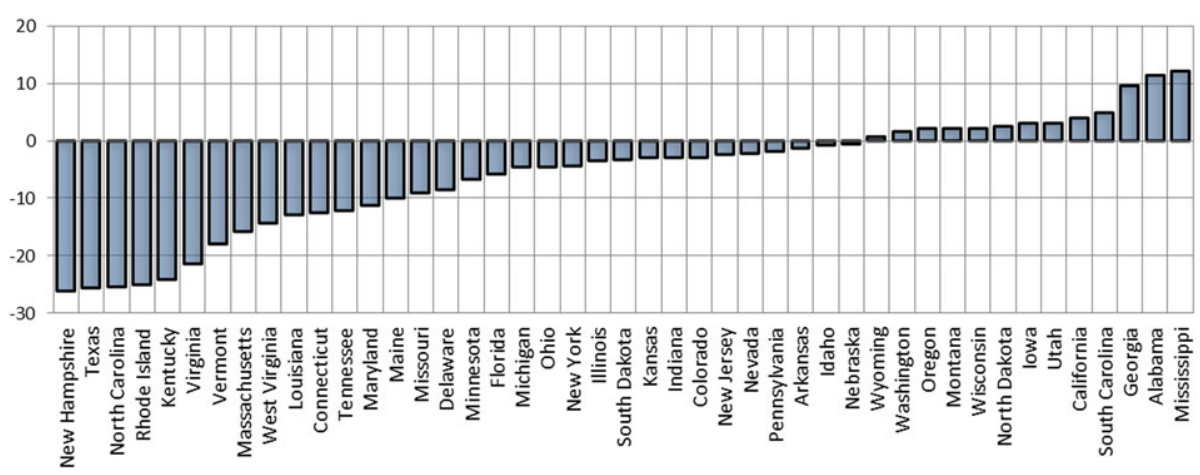

Fig. 8 Distance difference

in terms of the dissimilarity index vis-à-vis the national cycles: positive values represent an increase in dissimilarity while negative values represent an increase in similarity. Clearly, most states have become more synchronized with the national cycle after the 1950s than they were in the preceding period. To test formally the hypothesis that cycles have become generally more synchronized, one can compute the mean and the variance of the distances in each sub-sample and perform a simple t-test against the null hypothesis that the mean is the same in both sub-samples. This can be performed either by computing the mean of the distances between every pair of states or computing the mean between the distance from each state to the aggregate. In both cases, the results statistically are clear: the null of equal means is rejected against the alternative that the mean distance has decreased, at the $1 \%$ significance level. In sum, from the first to the second half of the 20th century, electoral cycles in the states have indeed become more synchronized with the national cycle.

Having said that, there are clear exceptions: Alabama, Mississippi, and Georgia have strikingly become more peripheral in the second half of the sample. If there is a tendency towards the "universality of political trends" in presidential elections in the United States, the evidence suggests that these four states have been mostly impervious to it.

A second way of summarizing the results is to calculate the aggregate Democratic share of the two-party vote for the three groups of states we identified early on and estimate the cross wavelets and phase-differences pertaining to their cycles. The three groups are formed by the four states of the "Deep South" cluster; the "Outer South" cluster (the remaining Southern states plus Kentucky); and the "core" states. In Fig. 9, it is clear that the Deep South states have not approached the core, with almost no regions of coherence and messy phase-differences, showing no sign of alignment with the core states. On the other hand, one can see that the rest of the South has indeed converged to the core. This is particularly evident when one looks at the phases in the 12-16 year frequency band, where coherency becomes evident starting at about 1950 .

In sum, the evidence obtained by means of wavelet analysis paints a somewhat different picture from that presented in Schantz (1992) and Bartels (1998) concerning the timing of greater dynamic nationalization of presidential elections. Overall, we do confirm the existence of such a change, by identifying the states in which electoral cycles have become more in sync than in the past. But as Schattschneider suggested, the 1932 election and the New Deal was neither the single nor necessarily the most important event to consolidate a system where presidential election, regardless of the level of support enjoyed by each party in a particular groups of states, became driven by common national forces across a majority of states. It is the 1950 s, not the 1930 s, that seem to constitute the decisive turning 
(a) Deep South vs Core

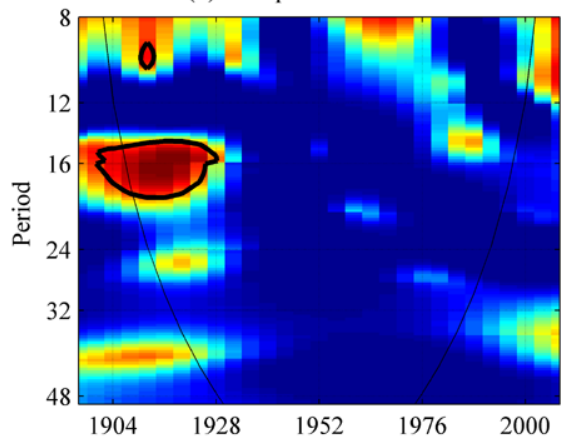

(a) South vs Core

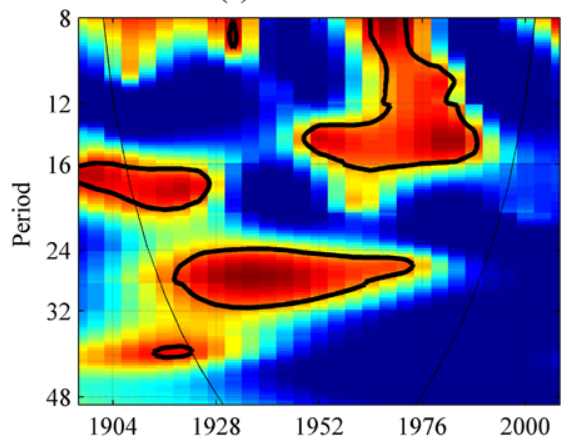

(b) 12 16 frequency band

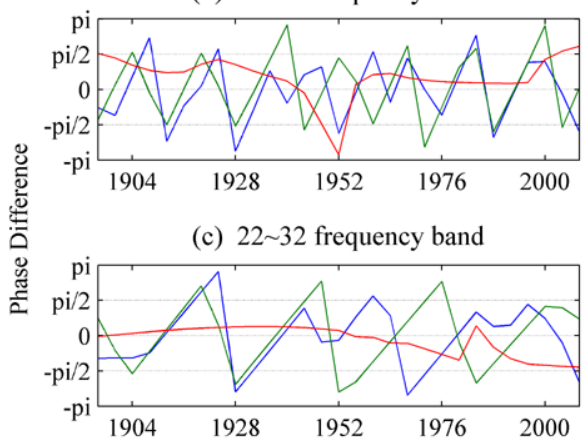

(b) 12 16 frequency band

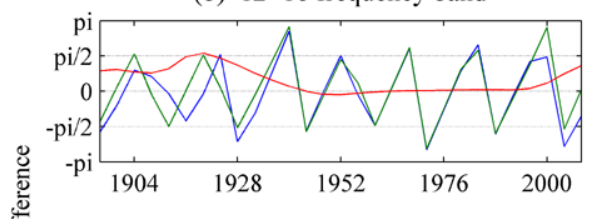

(c) 22 32 frequency band

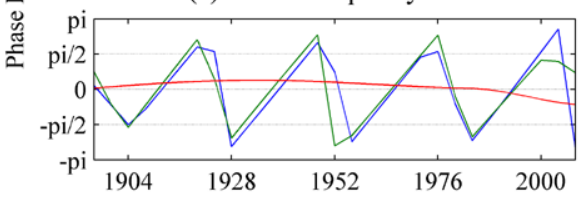

Fig. 9 Wavelet coherency core/deep South and core/South (Color figure online)

point in terms of the synchronicity in electoral cycles both among the states and between the states and the national cycle. Important as the "revolution" of 1932 may have been, other developments-World War II, the Cold War and how they changed the "meaning of American politics" (Schattschneider 1960), the post-war nationalization of the news media (Schudson 1995), and especially the Southern realignment (Nardulli 1995) and the "nationalization of turnout" (McDonald 2010) — seem too important not to have made a difference in the extent to which, in spite of lingering sectional patterns, presidential elections across the country have become driven by national forces.

Furthermore, we can see now with more precision where decisive developments driving this convergence in electoral cycles have occurred: the phase-difference between the "core" states and most of the Southern states, particularly in the 12-16 frequency band, starts approaching zero by the 1950s, suggesting a convergence with the electoral cyclicality that already characterized most of the core states. The same, however, has not occurred in the Deep South, where convergence has failed to materialize in the second half of the decade. Such a finding may seem surprising, given the prevalent notion of how the disappearance of the Democratic "solid South," and the ensuing party polarization in Congress, has brought about a truly nationalized party system (Petrocik 1987; Rohde 1991; Shafer and Johnston 2006). On the other hand, however, others have noted how politics in the Deep South has preserved important specificities in terms of socio-demographic composition, racial attitudes, partisanship, and voting (Black and Black 2010). For example, while it quite took longer than in the other southern states for Republican presidential candidates to start getting a majority of the votes from white voters in the Deep South, the decline of 
the Democrats since then, both in terms of election results and party identification, has also been more dramatic there than in the rest of the South (Valentino and Sears 2005; Hayes and McKee 2008; Kousser 2010).

\section{Conclusion}

In this paper, we analyzed the dynamic nationalization of presidential elections in the United States. Taking states-the natural battlegrounds of elections for an Electoral College majority - as our basic unit of analysis, we focused on the divergence or convergence of electoral movements across the American polity. Complementing extant research on the geography of electoral support in the United States, we searched for patterns distinguishing groups of states characterized by high and low synchronism in electoral cycles, both among each other and with the national aggregate. Then, we analyzed trends in the extent to which such cycles have become more or less synchronized from 1896 until today. For these purposes, we resorted to the tools of wavelets analysis, an innovative and highly promising approach to the study of time series data.

We found, first, that a rather meaningful division between states emerges when we look for similarities and differences in the cyclicality of electoral returns, separating a large number of "core" states from the remaining old Confederacy states. Within the South, an additional division emerges, allowing us to identify the "Deep South states" as those that have been characterized by electoral cycles that have remained asynchronous with the rest of the United States and, furthermore, have shown no signs of convergence in electoral trends. These are states that have remained impervious to the ebb and flow of electoral returns that previous research has shown to characterize the national aggregate (Lin and Guillén 1998; Merrill et al. 2008; Aguiar-Conraria et al. 2012a).

We also provided additional evidence concerning a rising dynamic nationalization of politics in American elections. Schattschneider's original argument was that the New Deal, albeit a crucial step in the nationalization of American politics, was not a sufficient condition, and had to be complemented by the accumulation of additional developments that contributed to a greater relevance of the federal government. Others, however, have dated the most dramatic change in this respect to the period of the New Deal and saw more modest changes in dynamic nationalization afterwards. Our evidence, using wavelet analysis, suggests that dynamic nationalization in US presidential elections seems to be, in fact, mostly a post-war phenomenon. The fact that an important part of such stronger nationalization in presidential electoral politics resulted from the convergence in electoral cycles in most of the South with the national core since the 1950s suggests that the electoral realignment and the expansion of voting rights clearly line up, in spite of the resilient uniqueness of the Deep South, as plausible proximate causes in bringing about an increased "universality of political trends" in presidential elections.

Acknowledgements Earlier versions of this article were presented at the American Political Science Association meeting in September 2010, at the Department of Economics of the University of Minho, and at the Lisbon Group for Institutions and Public Policy of the Nova School of Business and Economics and the Institute of Social Sciences of the University of Lisbon. We are grateful for all the comments we received there. We thank the editors of Public Choice and three anonymous reviewers for the comments and suggestions they provided. We would also like to express our gratitude to Bernard Grofman, Paul A. Beck, Samuel Merrill, and Thomas L. Brunell for their comments to earlier versions of the paper and for their encouragement. Pedro C. Magalhães worked in this article while he was FLAD Visiting Professor at the Department of Government of Georgetown University, and wishes to thank and the department and the Luso-American Foundation for their support. 


\section{References}

Agnew, J. A. (1987). The United States in the world economy. Cambridge: Cambridge University Press.

Aguiar-Conraria, L., \& Soares, M. J. (2011). Business cycle synchronization and the Euro: a wavelet analysis. Journal of Macroeconomics, 33(3), 477-489.

Aguiar-Conraria, L., \& Soares, M. J. (2013, forthcoming). The continuous wavelet transform: moving beyond uni and bivariate analysis. Journal of Economic Surveys.

Aguiar-Conraria, L., Magalhães, P. C., \& Soares, M. J. (2012a). Cycles in politics: Wavelet analysis of political time-series. American Journal of Political Science, 56(2), 500-518.

Aguiar-Conraria, L., Martins, M. M. F., \& Soares, M. J. (2012b). The yield curve and the macro-economy across time and frequencies. Journal of Economic Dynamics and Control, 36(12), 1950-1970.

Alvarez, R. M., \& Nagler, J. (1995). Economics, issues, and the Perot candidacy: voter choice in the 1992 presidential election. American Journal of Political Science, 39(3), 714-744.

Archer, J. C., \& Shelley, F. M. (1986). American electoral mosaics. Washington: Association of American Geographers.

Archer, J. C., \& Taylor, P. J. (1981). Section and party: a political geography of American presidential elections, from Andrew Jackson to Ronald Reagan. Chichester: Research Studies Press.

Bartels, L. M. (1998). Electoral continuity and change, 1868-1996. Electoral Studies, 17(3), 301-326.

Black, M., \& Black, E. (2010). Deep South politics: the enduring racial division in national elections. In C. S. Bullock III \& M. J. Rozell (Eds.), The Oxford handbook of Southern politics (pp. 401-426). New York: Oxford University Press.

Brady, D. W., D’Onofrio, R., \& Fiorina, M. (2000). The nationalization of electoral forces revisited. In D. Brady, J. Cogan, \& M. Fiorina (Eds.), Continuity and change in House elections (pp. 130-148). Stanford: Stanford University Press.

Burden, B. C., \& Wichowsky, A. (2010). Local and national forces in congressional elections. In J. E. Leighley (Ed.), The Oxford handbook of American elections and political behavior (pp. 453-470). Oxford: Oxford University Press.

Cazelles, B., Chavez, M., Berteaux, D., Ménard, F., Vik, J. O., Jenouvrier, S., \& Stenseth, N. (2008). Wavelet analysis of ecological time series. Oecologia, 156, 287-304.

Claggett, W., Flanigan, W., \& Zingale, N. (1984). Nationalization of the American electorate. The American Political Science Review, 78(1), 77-91.

Clotfelter, C. T., \& Vavrichek, B. (1980). Campaign resource allocation and the regional impact of electoral college reform. Journal of Regional Science, 20, 311-329.

Crowley, P. (2007). A guide to wavelets for economists. Journal of Economic Surveys, 21(2), 207-267.

Elazar, D. J. (1994). The American mosaic: the impact of space, time, and culture on American politics. Boulder: Westview Press.

Gallegati, M., Ramsey, J., \& Semmler, W. (2011). The US wage Phillips curve across frequencies and over time. Oxford Bulletin of Economics and Statistics, 73, 489-508.

Hayes, D., \& McKee, S. C. (2008). Toward a one-party South? American Politics Research, 36(1), 3-32.

Heppen, J. (2003). Racial and social diversity and U.S. presidential election regions. The Professional Geographer, 55, 191-205.

Hero, R. E. (1998). Faces of inequality: social diversity in American politics. New York: Oxford University Press.

Kawato, S. (1987). Nationalization and partisan realignment in congressional elections. The American Political Science Review, 81(4), 1235-1250.

Kennedy, P. (2008). A guide to econometrics (6th ed.). Cambridge: Wiley-Blackwell.

Kousser, J. M. (2010). The immutability of categories and the reshaping of Southern politics. Annual Review of Political Science, 13, 365-383.

Kruskal, J. B. (1964a). Multidimensional scaling by optimizing goodness of fit to a nonmetric hypothesis. Psychometrika, 29, 1-27.

Kruskal, J. B. (1964b). Nonmetric multidimensional scaling: a numerical method. Psychometrika, 29, 115129.

Lichtman, A. J. (1976). Critical election theory and the reality of American presidential politics, 1916-40. The American Historical Review, 81, 317-351.

Lin, T.-M., \& Guillén, M. (1998). The rising hazards of party incumbency: a discrete renewal analysis. Political Analysis, 7(1), 31-57.

Mayhew, D. R. (2002). Electoral realignments: a critic of an American genre. New Haven: Yale University Press.

McDonald, M. P. (2010). American voter turnout in historical perspective. In J. E. Leighley (Ed.), The $O x$ ford handbook of American elections and political behavior (pp. 125-143). Oxford: Oxford University Press. 
Merrill, S., Grofman, B., \& Brunell, T. L. (2008). Cycles in American national electoral politics, 1854-2006: statistical evidence and an explanatory model. American Political Science Review, 102(1), 1-17.

Morgenstern, S., Swindle, S. M., \& Castagnola, A. (2009). Party nationalization and institutions. The Journal of Politics, 71(04), 1322-1341.

Murray, A. T. (2010). Quantitative geography. Journal of Regional Science, 50, 143-163.

Nardulli, P.F. (1995). The concept of a critical realignment, electoral behavior, and political change. American Political Science Review, 89, 10-22.

Norpoth, H. (1995). Is Clinton doomed? An early forecast for 1996. PS: Political Science and Politics, 28(2), 201-207.

Petrocik, J. R. (1987). New party coalitions and the nationalization of the South. The Journal of Politics, 49(2), 347-375.

Rohde, D. W. (1991). Parties and leaders in the postreform House. Chicago: University of Chicago Press.

Rua, A. (2012). Money growth and inflation in the Euro area: a time-frequency view. Oxford Bulletin of Economics and Statistics, 74(6), 875-885.

Schantz, H. L. (1992). The erosion of sectionalism in presidential elections. Polity, 24(3), 355-377.

Schattschneider, E. E. (1960). The semisovereign people. New York: Holt, Rinehart and Winston.

Schudson, M. (1995). The power of news. Cambridge: Harvard University Press.

Shafer, B. E., \& Johnston, R. (2006). The end of Southern exceptionalism: class, race, and partisan change in the postwar South. Cambridge: Harvard University Press.

Shelley, F. M., Archer, J. C., Davidson, F. M., \& Brunn, S. D. (1996). Political geography of the United States. New York: Guilford Press.

Stokes, D. (1967). Parties and the nationalization of electoral forces. In W. Chambers \& W. Burnham (Eds.), The American party systems: stages of political development (pp. 182-202). New York: Oxford University Press.

Turner, F. J. (1914). Geographical influences in American political history. Bulletin of the American Geographical Society, 46(8), 591-595.

Turner, F. J. (1926). Geographic sectionalism in American history. Annals of the Association of American Geographers, 16(2), 85-93.

Valentino, N. A., \& Sears, D. O. (2005). Old times are not forgotten: race and partisan realignment in the contemporary South. American Journal of Political Science, 49(3), 672-688.

Vertz, L. L., Frendreis, J. P., \& Gibson, J. L. (1987). Nationalization of the electorate in the United States. The American Political Science Review, 81(3), 961-966. 